\title{
VSÄ im Schweizerischen Studentinnenmuseum
}

\author{
U. Pfister
}

Wussten Sie, dass die Schweiz ein Museum über die Geschichte ihrer Studentinnen hat? Ehrlich gesagt, wir bis vor kurzem auch nicht. Um so neugieriger folgten ein paar VSÄ-Vorstandsfrauen der Einladung des Museumsleiters nach Assens VD.

Im kleinen, aber feinen Museum - untergebracht im Espace culturel Assens, in malerischer Landschaft etwas nördlich von Lausanne wurden wir von Giovanni Lanfranconi, dem Initiator der Ausstellung, herzlich empfangen. Er führte uns durch das Studentinnenmuseum, das mit bescheidenen Mitteln, aber auf beeindruckende Weise die reiche - und leider ziemlich unbekannte - Geschichte der Studentinnen in unserem Land zeigt.

\section{Rückkehr zu den Wurzeln}

Die Geschichte der Studentinnen in der Schweiz ist gleichzeitig auch die Geschichte der ersten Ärztinnen in unserem Land: Die ersten Frauen an einer Schweizer Universität waren nämlich Humanmedizinerinnen.

Eine eindrückliche Ahnengalerie listet den bis heute bekannten Teil der Pionierinnen an unseren Universitäten auf. Die Ausstellungsmacherinnen haben viel Recherchierarbeit geleistet. Trotzdem sind nicht alle Frauen aufgelistet, die zu Beginn der Frauenära an den
Universitäten eingeschrieben waren. Das hat auch damit zu tun, dass viele Unterlagen verschwunden sind oder irgendwo unerkannt vor sich hin dümpeln.

Im Museum nimmt Nadeschda Prokolewna Suslowa, die 1867 an der Universität Zürich zur Doktorin der Medizin promovierte, stellvertretend für alle Frauen ihrer Generation einen Ehrenplatz ein: Sie war nicht nur die erste Frau in der Schweiz, sondern im ganzen deutschsprachigen Raum, die an einer staatlich anerkannten Universität ein reguläres Studium abschloss. Ihr Foto kann ebenso bestaunt werden wie diejenigen ihrer immer zahlreicher werdenden Nachfolgerinnen.

\section{Zu Beginn kaum Schweizer Studentinnen}

Russische Studentinnen waren die Vorkämpferinnen des Frauenstudiums bei uns. Ab 1860 an der Universität St. Petersburg als Hörerinnen zugelassen, wurden sie bereits 1863 wieder vom Studium ausgeschlossen und mussten ins Ausland ausweichen. So kamen sie auch nach Zürich.

Schweizer Studentinnen gab es zur selben Zeit kaum. Für sie war der Hochschulzugang faktisch unmöglich, weil keine vorbereitenden Gymnasien für Mädchen existierten. Wer trotz dieser Widrigkeiten ein Studium schaffte, fand häufig keine Assistenzstellen.

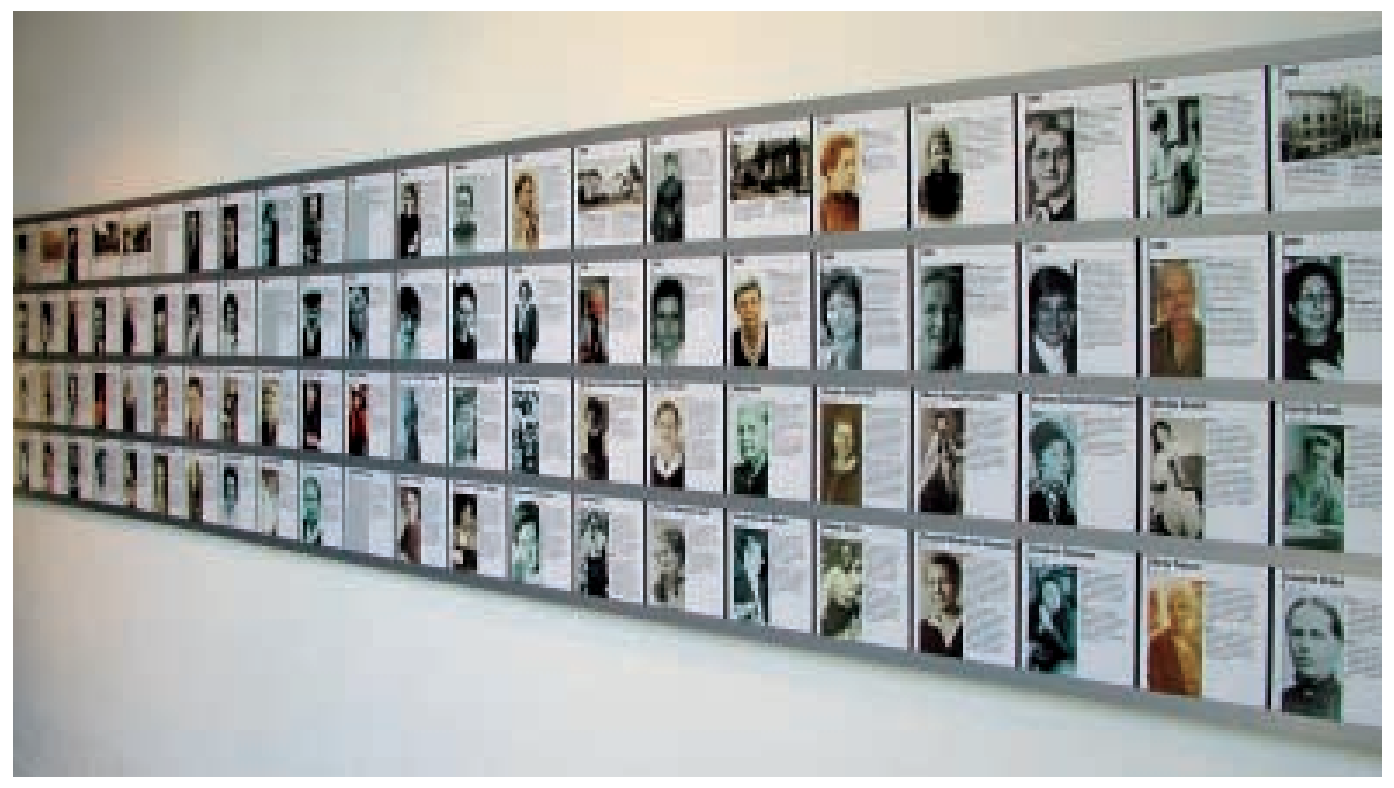


Erst nach 1915 waren an den Schweizer Universitäten mehr Schweizerinnen als Russinnen $\mathrm{zu}$ finden. Ihre Berufsmöglichkeiten blieben jedoch weiterhin beschränkt. Ärztinnen, Apothekerinnen und Anwältinnen wählten meist die selbständige Tätigkeit, die Frauen aus den geistes- und naturwissenschaftlichen Disziplinen engagierten sich vor allem in der Mädchenbildung.

\section{Espace culturel}

Das Studentinnenmuseum ist im Haus des Espace culturel Assens untergebracht, wo wechselnde Ausstellungen jungen Schweizer Künstlern Raum geben, ihre neuesten Werke zu präsentieren.
Der Espace culturel geniesst in der Romandie einen sehr guten Ruf. Nicht zuletzt dazu beigetragen hat eine grosse Skulpturenausstellung aus dem letzten Jahr: Die einzelnen Werke standen nicht im Museum - das wäre dafür viel zu klein -, sondern draussen in der Landschaft rund um das Dorf Assens. Von dieser einmaligen Aktion zeugt noch immer der sehr schöne Ausstellungskatalog.

Das Studentinnenmuseum ist zu den gleichen Zeiten geöffnet wie der Espace culturel (Do/Fr 16-19, Sa/So 11-17 Uhr). Mehr Informationen finden Sie im Internet unter www. espace-culturel.ch.

\section{Kongress der Schweizerischen Gesellschaft für Allgemeinmedizin}

\section{1.-23. Oktober 2004, BEA bern expo \\ Die FMH}

wünscht allen Teilnehmerinnen und Teilnehmern einen interessanten Kongress.

Besuchen Sie uns am Stand Nr. 8, Halle 130

Kommen Sie mit Ihren Fragen und Anliegen: Wir sind für Sie da!

Nutzen Sie die Gelegenheit, an unserem Stand eine neue

Online-Fortbildung zu testen:

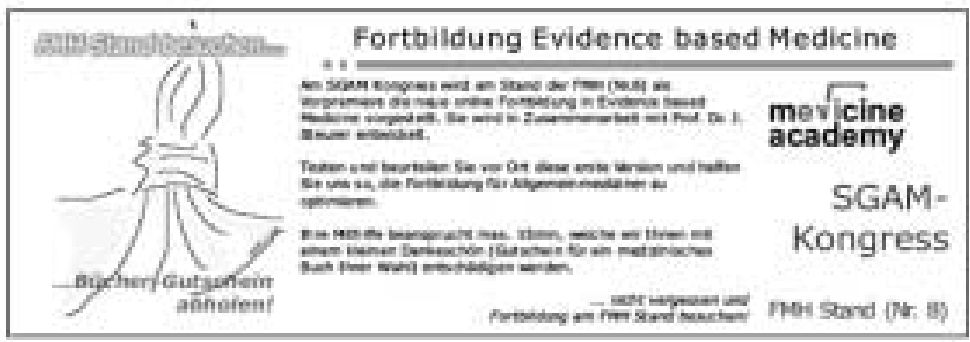

